\title{
Vidarabine Anhydrous
}

National Cancer Institute

\section{Source}

National Cancer Institute. Vidarabine Anhydrous. NCI Thesaurus. Code C77393.

An anhydrous form of vidarabine, a nucleoside analog with activity ag ainst herpes

simplex virus and varicella zoster virus. Vidarabine is converted to a monophosphate by viral thymidine kinase and is further modified to a triphosphate form by host enzymes.

Vidarabine triphosphate directly inhibits DNA polymerase and also acts as a chain terminator in DNA replication. 